\title{
Early risk pathways to physical versus relational peer aggression: The interplay of externalizing behavior and corporal punishment varies by child sex
}

\author{
Courtney A. Zulauf $\mathrm{MA}^{1}$ \\ Sheryl L. Olson PhD ${ }^{4}$
}

\author{
Alexander W. Sokolovsky PhD ${ }^{2}$ | Adam S. Grabell PhD ${ }^{3}$ |
}

1 Psychology Department, University of Illinois at Chicago, Chicago, Illinois

2 Alpert Medical School, Brown University,

Providence, Rhode Island

${ }^{3}$ Department of Psychological and Brain Sciences, University of Massachusetts,

Amherst, Amherst, Massachusetts

4 Psychology Department, The University of

Michigan, Ann Arbor, Michigan

Correspondence

Courtney Zulauf, MA, Psychology

Department, University of Illinois at Chicago,

1007 W Harrison Street, BSB 1506, Chicago,

IL 60607.

Email: czulau2@uic.edu

Funding information

National Institute of Mental Health,

Grant number: R01MH57489

\begin{abstract}
Children who aggress against their peers may use physical or relational forms, yet little research has looked at early childhood risk factors and characteristics that uniquely predict high levels of relational versus physical aggression in preadolescence. Accordingly, the main aim of our study was to link early corporal punishment and externalizing behavior to children's physical and relational peer aggression during preadolescence and to examine how these pathways differed by sex. Participants were 193, 3-year-old boys (39\%) and girls who were reassessed following the transition to kindergarten (5.5 years) and preadolescence (10.5 years). A series of autoregressive, cross-lagged path analyses were conducted to examine the relationships between child externalizing problems and corporal punishment at ages 3 and 5.5 years, and their association with physical and relational aggression at age 10.5. Multiple group analysis was used to determine whether pathways differed by sex. Three developmental pathways were identified: (i) direct associations between stable childhood externalizing problems and later physical aggression; (ii) a direct pathway from early corporal punishment to preadolescent relational and physical peer aggression; and (iii) an indirect pathway from early corporal punishment to later physical aggression via continuing externalizing problems in middle childhood. Child sex moderated the nature of these pathways, as well as the direction of association between risk and outcome variables. These data advance our understanding of the etiology of distinct forms of peer aggression and highlight the potential for more efficacious prevention and intervention efforts in the early childhood years.
\end{abstract}

\section{KEYWORDS}

corporal punishment, externalizing problems, longitudinal, parenting, peer aggression

\section{1 | INTRODUCTION}

Peer aggression encompasses a broad range of harmful behavior that places perpetrators and their victims at risk for a diverse range of negative developmental outcomes (Crick, Casas, \& Mosher, 1997; Crick \& Grotpeter, 1995; Hanish \& Guerra, 2002; Kochenderfer-Ladd
\& Skinner, 2002; Leadbeater \& Hoglund, 2009; Salmivalli \& Kaukiainen, 2004). Understanding early childhood precursors of individual differences in children's school-age peer aggression has important implications for theory and prevention. Peer aggression can take a physical form, for example hitting a classmate, or a relational form such as spreading a rumor about a classmate (Crick \& Grotpeter, 
1995). Although researchers have linked early child characteristics and parenting practices to later physical peer aggression, relatively little is known about early childhood precursors of relational forms of peer aggression. In the current study, we therefore tested a model linking early corporal punishment and child externalizing behavior to children's physical and relational peer aggression during preadolescence, and examined how these pathways differed for boys and girls.

\section{2 | EARLY EXTERNALIZING BEHAVIOR AS A PATHWAY TO PHYSICAL VERSUS RELATIONAL PEER AGGRESSION}

Early onset externalizing problems, defined as age-inappropriate levels of aggressive, disruptive and noncompliant behavior, place young children at risk for a broad range of negative developmental outcomes that include high levels of current and later peer rejection (Barker et al., 2008; Campbell, Shaw, \& Gilliom, 2000; Campbell, Spieker, Vandergrift, Belsky, \& Burchinal, 2010; Hughes, White, Sharpen, \& Dunn, 2000; Keane \& Calkins, 2004; Keown \& Woodward, 2006; Lansford, Malone, Dodge, Pettit, \& Bates, 2010). Moffitt (1993) found that a small proportion of children that show early-onset externalizing behavior will follow persistent developmental pathways with lasting externalizing problems well into adulthood. Previous work has also shown that high levels of externalizing behavior in preschool who is stable across entry into school predicts physical aggressive behavior (Hughes et al., 2000; Keown \& Woodward, 2006; Olson, Lopez-Duran, Lunkenheimer, Chang, \& Sameroff, 2011). Taken together, early onset externalizing problems, especially when stable across the school-age years, comprise a well-established pathway to later physical peer aggression. However, far less is known about early childhood pathways to children's later relational aggression, defined as indirect harm to others such as gossip, ostracism, and/or hostile manipulation of peer relationships (for review of relational aggression and similar constructs see Archer \& Coyne, 2005; Björkqvist et al., 2001; Crick, Casas, \& Ku, 1999; Crick, Ostrov, \& Werner, 2006). Evidence suggests that greater cognitive skills such as social cognition and behavioral selfregulation uniquely predict relational peer aggression (McQuade, Breaux, Miller, \& Mathias, 2017; Renouf et al., 2010). These cognitive skills are often not observed among children who use physical peer aggression and are skills that children with externalizing problems struggle with (Andreou, 2006; Kaukiainen et al., 1999; Vaillancourt, Brendgen, Boivin, \& Tremblay, 2003). As a result, early externalizing problems may differentially predict relational and physical peer aggression. Though both forms of peer aggression are interrelated and perpetrated by both sexes, relational aggression is the modal type of aggression for girls, whereas physical aggression is the modal type of aggression for boys (Ostrov \& Godleski, 2010). Therefore, studies that only include one type of peer aggression, usually physical aggression, may be overlooking a large subset of aggressive behavior that otherwise would not have been included. Thus, to understand the early childhood precursors of later peer aggression in both sexes, we considered physical and relational forms. As shown below, we highlighted the potential role of harsh parental physical discipline as a key precursor of individual differences in both forms of later peer aggression.

\section{I HARSH PARENTAL DISCIPLINE AS A PATHWAY TO PHYSICAL VERSUS RELATIONAL PEER AGGRESSION}

Harsh parental physical discipline, including corporal punishment, has been linked to elevated levels of peer aggression in children (Olson et al., 2011; Park et al., 2005; Schwartz, Dodge, Pettit, \& Bates, 2000). Harsh parental physical discipline provides parents with a power-assertive means of eliciting immediate compliance, modeling both relational and physical dominance vis-a-vis their children (Choe, Olson, \& Sameroff, 2013). Harsh parental discipline is often accompanied by negative emotions (i.e., anger, hostility, and frustration) as well as inconsistent care, evoking negative affect, and disrupting the child's ability to learn appropriate ways of regulating anger and conflict, thus placing the child at risk for future peer aggression (Critchley \& Sanson, 2006; Shields, Ryan, \& Cicchetti, 2001). For example, in a longitudinal study of preschool-age children who were followed across the transition to school, Olson et al. (2011) found that early parental corporal punishment predicted increased physical peer aggression across this transition period. Similarly, Park et al. (2005) found that mothers' negativity (defined as displeasure, disapproval, or criticism) toward their preschoolers predicted levels of children's overall peer aggression, defined as a composite of physical and relational aggression, in fifth grade. Clearly, harsh parental physical discipline is a key risk factor for children's concurrent and later peer aggression. However, we know relatively little about how early harsh parenting, more specifically the role of corporal punishment, in both preschool and the early school-age years, may differentially contribute to physical versus relational forms of peer aggression in preadolescence especially when child sex is considered, and our research was designed to address this gap in knowledge.

\section{I THE INTERPLAY OF HARSH PARENTAL DISCIPLINE, EXTERNALIZING BEHAVIOR, AND CHILD SEX}

Early individual differences in externalizing behavior, harsh parental discipline, and child sex may interact to predict different forms of future peer aggression. First, studies have shown that early externalizing problems and harsh parenting transact across development (Choe et al., 2013; Deater-Deckard \& Dodge, 1997; Gershoff, 2002). For example, Choe et al. (2013) showed that across a 7-year period spanning early childhood through preadolescence, parental physical discipline had a bidirectional relationship with child externalizing behavior over time. Similarly, Snyder, Cramer, Afrank, and Patterson (2005) demonstrated that maternal ratings of children's externalizing problems in kindergarten predicted adverse forms of maternal discipline, which in turn predicted high levels of child conduct problems, including physical peer aggression. 
Second, boys and girls may respond differently to harsh parental discipline. Social learning principles suggest that parents who rely on harsh parenting techniques may raise children who engage in similar behavior toward their peers. Children who are on the receiving end of harsh parental discipline may learn inappropriate ways to regulate anger and conflict from their parents' behavior (Critchley \& Sanson, 2006; Shields et al., 2001) and may demonstrate this learned behavior in their peer group. Harsh parenting behavior such as psychological control and manipulation closely reflects techniques that would be considered relational peer aggression. When it comes to sex differences, girls tend to view relational aggression as more common in their peer group, tend to direct this type of behavior at other girls, and view relational aggression as more harmful than boys do (for review see Merrell, Buchanan, \& Tran, 2006). This suggests that girls who receive harsh parental discipline consisting of control and manipulation may be more likely to use relational aggression. However, studies examining whether pathways from harsh discipline to relational aggression differ by sex have revealed mixed findings. For example, Nelson and Crick (2002) found that mothers' use of corporal punishment was positively associated with relational aggression for third grade boys only. However, Spieker et al. (2012) found that early maternal harsh control predicted relational aggression in third grade for girls but not boys. Further complicating these findings, studies that have focused only on physical peer aggression as an outcome have shown that harsh parental discipline predicts the use of physical peer aggression more so in boys than in girls (Gershoff, 2002; Patterson, Reid, \& Dishion, 1992). This may be because harsh parenting that includes physical discipline, such as corporal punishment, is more closely aligned with physical peer aggression. Therefore, there is reason to believe that harsh parental discipline may differently predict both future relational and physical peer aggression when child sex is taken into consideration. However, the strength and nature of these pathways are unclear.

It is important to note that although boys are more likely to use physical aggression than girls and when girls are aggressive they are more likely to use relational forms, sex differences in the use of relational peer aggression are complex. In fact, studies of sex differences in relational aggression have produced mixed findings with meta-analyses suggesting small sex differences (for review see Crick, Ostrov, \& Kawabata, 2007). As a result, researchers continue to caution that the evidence regarding sex differences in relational aggression is largely inconclusive, and that when exploring sex differences new techniques should be used (Bjorklund \& Pellegrini, 2000; Underwood, Galenand, \& Paquette, 2001). This complexity may be due to differences in gender socialization which may influence the form of aggression that girls and boys engage in. Specifically, even though sex differences for relational aggression do not appear to be as robust as previously believed, social goals and norms, such as the need for intimacy among girls and instrumental goals among boys, may influence the type of peer aggression that boys and girls utilize (Ostrov \& Godleski, 2010). Further complicating potential sex differences and pathways to peer aggression is the fact that peer aggression increases in preadolescence, especially in terms of relational peer aggression (Boivin, Petitclerc, Feng, \& Barker, 2010; Pellegrini \& Bartini, 2001).
Collectively, this literature suggests that transactions between externalizing behavior and harsh parenting may set the stage for elevated levels of physical and relational peer aggression in preadolescence, but the strength and nature of these pathways may be influenced by child sex.

\section{5 | THE CURRENT STUDY}

In the present study, we used a series of autoregressive, cross-lagged path analyses to examine the interplay between corporal punishment and early externalizing problems over time as pathways to physical versus relational peer aggression in preadolescence. We were interested in exploring several aspects of these pathways: (i) bidirectional relationships between corporal punishment and externalizing problems over time; (ii) the stability of corporal punishment and externalizing problems between early preschool and the transition to school; (iii) whether externalizing problems mediate links between early corporal punishment and later peer aggression; and (iv) possible direct pathways from preschool externalizing problems and corporal punishment to preadolescent physical and relational peer aggression. Based on prior research, we predicted that externalizing behavior and corporal punishment would differentially contribute to physical and relational forms of peer aggression. Specifically, we predicted that children's early externalizing behavior would contribute to physical peer aggression whereas corporal punishment would predict both physical and relational peer aggression. Finally, an exploratory analysis was whether girls and boys will follow different pathways from early externalizing behavior and corporal punishment to later peer aggression. However, because previous research has not accounted for both externalizing behavior and corporal punishment when looking at sex as a moderator of pathways to both relational and physical peer aggression we did not have specific hypotheses about how these pathways will differ by child sex. Rather, addressing gaps in prior research, our goal was to determine whether and how pathways between early childhood risk factors and later forms of peer aggression may differ for boys and girls.

\section{6 | METHOD}

\section{1 | Participants}

Participants were 240 children (118 girls; age range $=32-45$ months, $M=41.40$ months, $S D=2.09$ months) who were enrolled in an ongoing longitudinal study of young children at risk for school-age conduct problems (Olson, Sameroff, Kerr, Lopez, \& Wellman, 2005). Children represented the full range of externalizing symptom severity on the Child Behavior Checklist/2-3 (Achenbach, 1992), with an oversampling of toddlers in the medium high to high range of the Externalizing Problems Scale ( $T>60 ; 44 \%)$. The remaining sample was split relatively evenly between children whose externalizing problems $T$ scores exceeded 50 but were below 60 , and those whose $T$ scores were below 50. Most families (95\%) were recruited from newspaper announcements and fliers sent to day care centers and preschools 
while others were referred by preschool teachers and pediatricians. To recruit children with a range of behavioral adjustment levels, two different ads, one focusing on hard to manage toddlers, and the other on normally developing toddlers, were periodically placed in local and regional newspapers and childcare centers.

Among participating children, $94.8 \%$ were of European American heritage. Others were of African American (2.1\%), Hispanic American (1.6\%), and Asian American (1.6\%) racial or ethnic backgrounds. Most (90\%) resided in two-parent families; of the remaining households, $4.7 \%$ of parents identified themselves as single (never married), 3.1\% as divorced, and $2.1 \%$ as living with a partner. Four percent of mothers and $9 \%$ of fathers had achieved high school educations, $45 \%$ of mothers and $32 \%$ of fathers had completed 4 years of college, and $38 \%$ of mothers and $46 \%$ of fathers had completed additional graduate or professional training. The median annual family income based on the Hollingshead (1979) four-factor method was approximately $\$ 65,000$ (self-reported range $\$ 60,000-\$ 70,000$ ). Participating children were 3 years old at Time 1 (T1), 5.5 years old at Time 2 (T2), and 10.5 years old at Time 3 (T3).

\section{$6.2 \mid$ Measures}

\subsection{1 | Child externalizing behavior}

The Child Behavior Checklist (CBCL) Externalizing scale was used to measure individual differences in disruptive behavior and noncompliant behavior. Mothers $(n=193)$ completed the CBCL for ages 2-3 (CBCL/2-3; Achenbach, 1992) at T1 ( $\alpha=0.92)$. At T2 mothers ( $n=179)$ completed the CBCL for ages 4-18 (CBCL/4-18; Achenbach, 1991). The CBCL includes 99 items rated on a 3-point scale (from " 2 " = very true or often true of the child to " 0 " = not true of the child). The Externalizing scale (e.g., "punishment does not change his/her behavior") was used to measure child externalizing behavior $(\alpha=0.94)$. Items directly querying physical aggression (i.e., Q35 "gets in many fights," Q40 "hits others," Q53 "physically attacks people" for CBCL/2-3; Q37 "gets in many fights," Q57 "hits others" for CBCL/418) were subtracted from externalizing scale sum of total scores to reduce conceptual overlap.

\subsection{2 | Corporal punishment}

Dodge, Pettit, and Bates (1994) Harshness of Discipline scale was administered during home interviews at T1 and T2. This measure was found to have strong reliability ( $\alpha=0.97$; Dodge et al., 1994) and has shown consistent evidence of concurrent and predictive validity (e.g., Olson et al., 2005). Mothers reported the frequency with which each parent had physically disciplined their child (e.g., spank with a hand or object, grab, or shake) during the last 3 months using a 5-point scale: never (0), once per month (1), once per week (2), daily (3), and several times daily (4). Half point responses were accepted (e.g., once every 2 weeks [1.5]; every other day [2.5]; no responses of 3.5 or 4.5 were provided). Rank order scores from 0 to 35 were created based on the sum of mothers' reported frequencies of each parent's use of physical discipline. The lowest ranking, 0 , was assigned to children who did not receive physical discipline from either parent (i.e., responses of 0,0 ). Children assigned the next lowest ranking, 1 , did not receive physical discipline from one parent, but were physically disciplined once every 2 months by the other $(0,0.5)$. Children who experienced physical discipline several times daily from both parents received the highest ranking of $35(4,4)$. There were no responses of 3.5 , so the next highest ranking, 34 , indicated children who were physically disciplined daily by one parent and several times daily by the other $(3,4)$. Parents' use of physical discipline was relatively low in frequency $(M=1.06, S D=0.87$, range $=0-4$ for mother's report of her own use of physical discipline; $M=0.69, \mathrm{SD}=0.81$, range $=0-3$ for mother's report of the father's use of physical discipline). According to mothers, 58 children had never received physical discipline from either parent in the past 3 months; 16 children were physically punished every day or several times a day by at least one parent.

\subsection{3 | Physical and relational peer aggression}

At age 10 years, 193 teachers completed the Inventory of Peer Relations (Dodge \& Coie, 1987). This 12-item scale provides measures of reactive ("when teased, strikes back") and proactive ("bullies others") peer aggression. The scale has high internal consistency $(\alpha=0.92)$ and moderate construct validity (Dodge \& Coie, 1987). In addition, teachers completed the relational aggression subset of Crick's (1996) Children's Social Behavior Scale-Teacher Form (CSBS-T; the physical aggression subset was not used). The relational aggression subscale includes 7 items rated on a 5-point Likert scale (from $1=$ "never true" to $5=$ "almost always true"). An example item from the CSBS-T is "When angry at another kid, $\mathrm{s}$ /he tries to get other children to stop hanging around with or stop liking the kid." The CSBS-T has high internal consistency $(\alpha=0.93)$ and moderately high concurrent validity. The correlation among physical and relational aggression using these measures was strong $(r=0.66, p<.001)$. For both measures of aggression (CSBS-T and Inventory of Peer Relations) we used the sum of the items.

\section{3 | Analytic approach}

We first examined descriptive properties of our measures, including mean-level sex differences, correlations, and mean differences between study measures and demographics, as well as bivariate associations between study measures. Next, we conducted a series of autoregressive, cross-lagged path analyses examining relationships between early child externalizing problems and corporal punishment at T1 and T2, and their relationship to T3 physical and relational peer aggression outcomes. Finally, we used multiple group analysis to determine whether associations between these variables differed by child sex.

Multivariate path analyses were performed using lavaan 0.5-23 (Rosseel, 2012). Using path analysis for the modeling of data allowed us to simultaneously model (i) bidirectional relationships between our two predictor variables (i.e., early child externalizing problems and corporal punishment) over time; (ii) the stability of these predictors across T1 and T2; and (iii) the potential mediating role of T2 predictors 
between T1 and physical and relational peer aggression at T3. Furthermore, in addition to evaluating indirect pathways, this analytic approach allowed us to examine direct pathways between T1 or T2 predictors and outcome variables to evaluate their relative importance over time. We were also able to apply the model across multiple groups (i.e., sex) simultaneously and observed how the model fit and path parameters changed when equality constrains were applied (Kline, 2005).

We used several analytic strategies to establish the best fitting model and improve statistical validity. Among participants, missing T3 outcome data were not associated with study characteristics or sociodemographic factors. Among the remaining families $(n=193), 7.25 \%$ were missing early child externalizing problems at T2 and $23.32 \%$ missing corporal punishment at T2. Little's MCAR test (Little, 1988) was conducted to assess whether systematic missing data patterns were present, but it did not identify any $\left(\chi^{2}[20]=27.32, p=0.13\right)$. Therefore, data from all remaining families $(n=193)$ were included in our final models with missing data handled by full information maximum likelihood estimation. As a three-panel model with all direct and indirect effects specified is just-identified, we constrained nonsignificant zero or near-zero regression parameters to zero to improve model parsimony, over-identify the model, and allow for the evaluation of model fit. We calculated all indirect effects whose component paths were not constrained. We applied the best fitting model to the multi-group analysis prior to constraining regression parameters across child sex.

\section{7 | RESULTS}

\section{1 | Descriptive analysis}

Means, standard deviations, and ranges of externalizing problems, corporal punishment, and physical and relational peer aggression outcomes for both the overall sample and by child sex, are shown in Table 1. Pearson correlations between all modeled variables are shown in Table 2. Primary study variables did not differ across racial or ethnic backgrounds and were not correlated with other demographic factors except a significant negative relationship between mother's education and physical peer aggression ( $r=-0.23, p=.04)$. Mother's education was not significantly associated with other study predictors or outcome variables.

\section{2 | Path model}

We estimated several models to understand the relationship between early childhood externalizing problems, corporal punishment, and distal measures of physical and relational peer aggression among preadolescents. To test whether early externalizing behavior and corporal punishment would differentially contribute to physical versus relational forms of peer aggression, we fitted a model with freely estimated auto-correlated and cross-lagged pathways between our two-predictor variables at T1 and T2, as well as freely estimated paths between these predictors at $\mathrm{T} 2$ and each of the outcome measures at T3. Measures of childhood externalizing problems and corporal punishment were allowed to correlate at each of T1 and T2. This model was a poor fit for the data $\left(\chi^{2}=13.49, \mathrm{df}=4, p=.009\right.$; $\mathrm{CFI}=0.966, \mathrm{TLI}=0.871 ; \mathrm{RMSEA}=0.111$ ). Notably, there was no observed significant relationship between $\mathrm{T} 2$ corporal punishment and either physical or relational peer aggression at T3.

We fitted a second model, fixing these two nonsignificant paths to zero. This model fit better than our first model, but was still a mediocre fit for the data $\left(\chi^{2}=13.62, \mathrm{df}=6, p=.034 ; \mathrm{CFI}=0.972 \mathrm{TLI}=0.931\right.$; RMSEA $=0.081)$. Therefore, our third model specified the direct pathways between T1 predictors and T3 outcome variables, while continuing to constrain the paths between T2 corporal punishment and T3 outcomes to zero (Figure 1). Modification indices observed for our second model indicated that specifying these paths would significantly reduce model misfit. The third model fit significantly better than our second model $\left(\Delta \chi^{2}=11.16, \mathrm{df}=4, p=.025\right)$ and was a good fit for the data $\left(\chi^{2}=2.46, d f=2, \quad p=0.29 ; \quad C F I=0.998\right.$; $\mathrm{TLI}=0.987 ; \mathrm{RMSEA}=0.035$ ).

\subsection{Associations between corporal punishment and externalizing problems across time}

We first examined the stability of corporal punishment and externalizing problems from preschool to early childhood as well as their bidirectional affect on one another. Both corporal punishment $(\beta=0.191, \mathrm{SE}=0.053, p=.003)$ and externalizing problems $(\beta=0.431$, $\mathrm{SE}=0.055, p<.001)$ at T1 were associated with externalizing problems at T2. Corporal punishment at T1 was associated with T2 corporal punishment $(\beta=0.426, \mathrm{SE}=0.061, p<.001)$.

\section{4 | Predictors of physical and relational peer aggression}

\subsection{1 | Direct effects}

Next, we examined the direct pathways from externalizing problems and corporal punishment to preadolescent physical and relational peer aggression. Externalizing problems at $\mathrm{T} 2$ predicted physical aggression at T3 ( $\beta=0.310, \mathrm{SE}=0.053, p<.001)$ but not relational aggression at T3 $(\beta=0.149, \mathrm{SE}=0.072, p=.080)$. The direct paths from T1 externalizing problems to T3 physical aggression $(\beta=0.116$, $\mathrm{SE}=0.044, p=0.121)$ and T3 relational aggression $(\beta=-0.023$, $\mathrm{SE}=0.059, p=0.781)$ were not significant. Corporal punishment at T1 predicted both relational $(\beta=0.160, \mathrm{SE}=0.0521, p=.032)$ and physical $(\beta=0.141, \mathrm{SE}=0.038, p=.041)$ aggression at T3.

\subsection{2 | Indirect effects}

There was a significant indirect pathway between T1 corporal punishment and T3 physical aggression via T2 externalizing problems $(\beta=0.059, \mathrm{SE}=0.014, \quad p=.018)$. The significant direct pathway between T1 corporal punishment and T3 physical aggression suggests that T2 externalizing problems partially mediate this relationship. Additionally, the indirect pathway between $\mathrm{T} 1$ externalizing problems 
TABLE 1 Descriptive statistics by child sex at time point 1, time point 2, and time point 3

\begin{tabular}{|c|c|c|c|c|c|c|c|c|c|}
\hline Measures & \multicolumn{3}{|c|}{ Overall $(n=193)$} & \multicolumn{3}{|c|}{ Boys $(n=101)$} & \multicolumn{3}{|c|}{ Girls $(n=92)$} \\
\hline \multicolumn{10}{|l|}{ Time 1 (Age: $M=3.13 ; S D=0.23$ ) } \\
\hline CBCL 2-3 externalizing (mother) & 10.81 & $0-32$ & 6.41 & 10.99 & $0-32$ & 6.38 & 10.60 & $0-26$ & 6.48 \\
\hline Corporal punishment (mother) & 5.99 & $0-34$ & 6.78 & 6.92 & $0-34$ & 7.50 & 4.98 & $0-25$ & 5.76 \\
\hline \multicolumn{10}{|l|}{ Time 2 (Age: $M=5.28 ; S D=0.23$ ) } \\
\hline Corporal punishment (mother) & 4.26 & $0-32$ & 5.76 & 4.80 & $0-32$ & 6.44 & 3.56 & $0-25$ & 4.70 \\
\hline \multicolumn{10}{|l|}{ Time 3 (Age: $M=10.42 ; S D=0.64$ ) } \\
\hline Physical aggression (teacher) & 8.39 & $5-22$ & 3.79 & 9.01 & $5-22$ & 4.40 & 7.72 & $6-18$ & 2.85 \\
\hline Relational aggression (teacher) & 10.10 & $6-35$ & 4.66 & 9.85 & $7-22$ & 4.03 & 10.38 & $6-35$ & 5.27 \\
\hline
\end{tabular}

Valid observations are 193 for all variables at T1 and T3; 179 for CBCL 4-18 Externalizing ( 95 boys, 84 girls), and 148 for Corporal Punishment at T2 (84 boys, 64 girls). CBCL 2-3 and CBCL 4-18 externalizing scores represent total scores subtracting those items that directly query physical aggression.

and T3 physical aggression via T2 externalizing problems was significant $(\beta=0.134, \mathrm{SE}=0.023, p=.001$ ), suggesting that stability in early externalizing problems is associated with preadolescent physical aggression. Neither T1 corporal punishment $(\beta=0.028$, $\mathrm{SE}=0.013, p=.131)$ nor $\mathrm{T} 1$ externalizing $(\beta=0.064, \mathrm{SE}=0.027$, $p=.090$ ) were indirectly related to T3 relational aggression via T2 externalizing problems.

\section{5 | Measurement model by child sex}

To determine whether pathways to physical and relational peer aggression varied by child sex we refitted the above model across sex groups, constraining regression coefficients to be equal. The resulting model was a poor fit for the data $\left(\chi^{2}=33.04, \mathrm{df}=14, p=.003\right.$; $\mathrm{CFI}=0.938 ; \mathrm{TLI}=0.866 ; \mathrm{RMSE}=0.119$ ). The model freely estimating regression coefficients separately in the two sex groups was a good fit for the data $\left(\chi^{2}=6.50, \mathrm{df}=4, p=0.165 ; \mathrm{CFI}=0.992 ; \mathrm{TLI}=0.939\right.$; RMSEA $=0.080$ ) and fit significantly better than the constrained model $\left(\Delta \chi^{2}=26.54, \mathrm{df}=10, p=.003\right)$, suggesting the model allowing for sex differences was a superior fit of the data (Figures 2 and 3). Although the RMSEA of this model indicates somewhat mediocre fit to the data (i.e., RMSEA $=.05-0.10$ ), models with low $\mathrm{df}$ and smaller sample sizes have been shown to generate imprecise and artificially inflated RMSEA values (Kenny, Kaniskan, \& McCoach, 2015). The wide range of the $90 \% \mathrm{Cl}$ of the RMSEA in this model (0.000-0.188) demonstrates the imprecision of this estimate for this model. However, given that the RMSEA of this model is nevertheless greater than the typical cutoff of 0.05 for good fit, it is possible that there are other structural differences in these models across child sex. Modification indices observed for this model did not clarify these possible differences, with the largest indices of improved model fit suggesting paradoxical temporal relationships. As such, we decided to retain the current model.

\subsection{Associations between corporal punishment and externalizing problems by child sex}

Corporal punishment at T1 was associated with T2 externalizing problems among boys ( $\beta=0.217, \mathrm{SE}=0.068, p=.012$ ) but not among girls $(\beta=0.087, \mathrm{SE}=0.085, p=0.382)$. Externalizing problems at $\mathrm{T} 1$ were associated with $\mathrm{T} 2$ externalizing problems among both boys $(\beta=0.488, \mathrm{SE}=0.079, p<.001)$ and girls $(\beta=0.364, \mathrm{SE}=0.076$, $p<.001)$. Corporal punishment at T2 was associated with T1 corporal punishment for both boys $(\beta=0.402, \mathrm{SE}=0.086, p<.001)$ and girls

TABLE 2 Correlations among child externalizing behavior, corporal punishment, physical peer aggression, and relational peer aggression

\begin{tabular}{|c|c|c|c|c|c|c|}
\hline & 1 & 2 & 3 & 4 & 5 & 6 \\
\hline (1) T1 CBCL 2-3 externalizing & - & $0.29^{* *}$ & $0.49^{* *}$ & 0.20 & $0.31^{* *}$ & 0.10 \\
\hline (2) T1 corporal punishment & 193 & - & $0.32^{* *}$ & $0.46^{* *}$ & $0.27^{* *}$ & $0.20^{*}$ \\
\hline (4) T2 corporal punishment & 148 & 148 & 141 & - & 0.10 & 0.04 \\
\hline (5) T3 physical aggression & 193 & 193 & 179 & 148 & - & $0.66^{* *}$ \\
\hline
\end{tabular}

Two-tailed Pearson correlations are reported above the diagonal, while $N$ for each correlation is displayed below diagonal. T1, Data Collection at Time 1 (3 years old); T2, Data Collection at Time 2 (5.5 years old); T3, Data Collection at Time 3 (10.5 years old). CBCL 2-3 and CBCL 4-18 externalizing scores represent total scores subtracting those items that directly query physical aggression. ${ }^{*} p<.05 ;{ }^{* *} p<.01$ 
Age 3

Age 5.5

Age 10.5

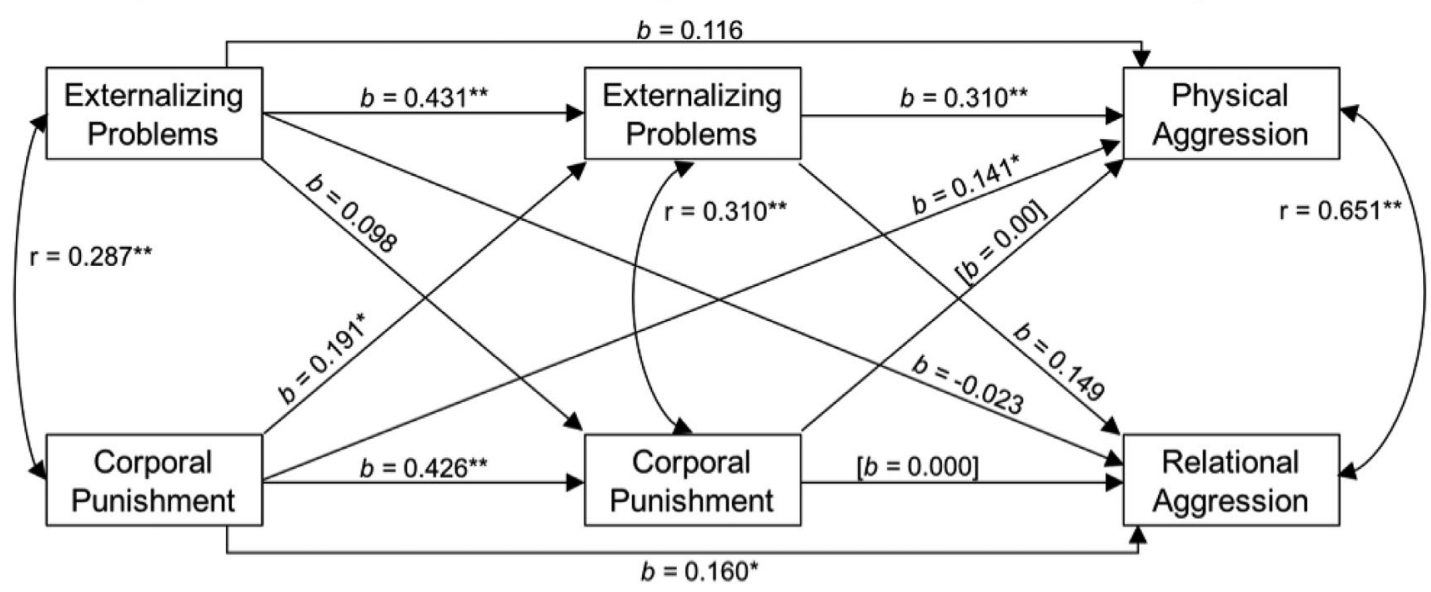

FIGURE 1 Cross-lagged panel analysis of T1 and T2 externalizing problems and corporal punishment predicting T3 physical and relational aggression. Shown are standardized regression coefficients $(b)$ and correlations $(r)$ for path models predicting adolescent (T3) physical and relational peer aggression from early childhood (T1 and T2) externalizing problems and corporal punishment. The [bracketed] pathways between T2 corporal punishment and T3 outcomes was fixed at zero as they were found to be n.s. Coefficients signified with an asterisk are significant. ${ }^{*} p<.05,{ }^{* *} p<.01$

$(\beta=0.427, \mathrm{SE}=0.083, p<.001)$, but was not associated with $\mathrm{T} 1$ externalizing problems for either sex (boys: $\beta=0.160, \mathrm{SE}=0.102$, $p=0.111$; girls: $\beta=0.021$, SE $=0.077, p=0.847$ ).

\section{7 | Predictors of physical and relational peer aggression by child sex}

Externalizing problems at T2 predicted T3 physical aggression among both boys $(\beta=0.305, \mathrm{SE}=0.080, p=.004)$ and girls $(\beta=0.264$, $\mathrm{SE}=0.066, p=.021$ ), but not T3 relational aggression for either sex (boys: $\beta=0.121, \mathrm{SE}=0.080, p=0.298$; girls: $\beta=0.154, \mathrm{SE}=0.121$, $p=0.173)$. Among boys, T1 externalizing problems predicted both T3 physical aggression $(\beta=0.244, \mathrm{SE}=0.072, p=.019)$ and T3 relational aggression $(\beta=0.276, \mathrm{SE}=0.072, p=.016)$. In contrast, $\mathrm{T} 1$ corporal punishment predicted neither T3 physical aggression $(\beta=0.092$, $\mathrm{SE}=0.055, \quad p=0.326)$ nor T3 relational aggression $(\beta=0.039$, $\mathrm{SE}=0.055, p=0.705)$ among boys. Among girls, T1 externalizing problems were not associated with T3 physical aggression $(\beta=-0.035$, $\mathrm{SE}=0.048, p=0.751$ ). Surprisingly, among girls, T1 externalizing problems were negatively related to T3 relational aggression $(\beta=-0.227, \mathrm{SE}=0.088, p=.036)$ revealing an opposite association from that found among boys. In contrast, T1 corporal punishment predicted T3 relational aggression among girls $(\beta=0.274, \mathrm{SE}=0.092$, $p=.006)$, but not physical aggression $(\beta=0.121, \mathrm{SE}=0.050, p=.235$ ).

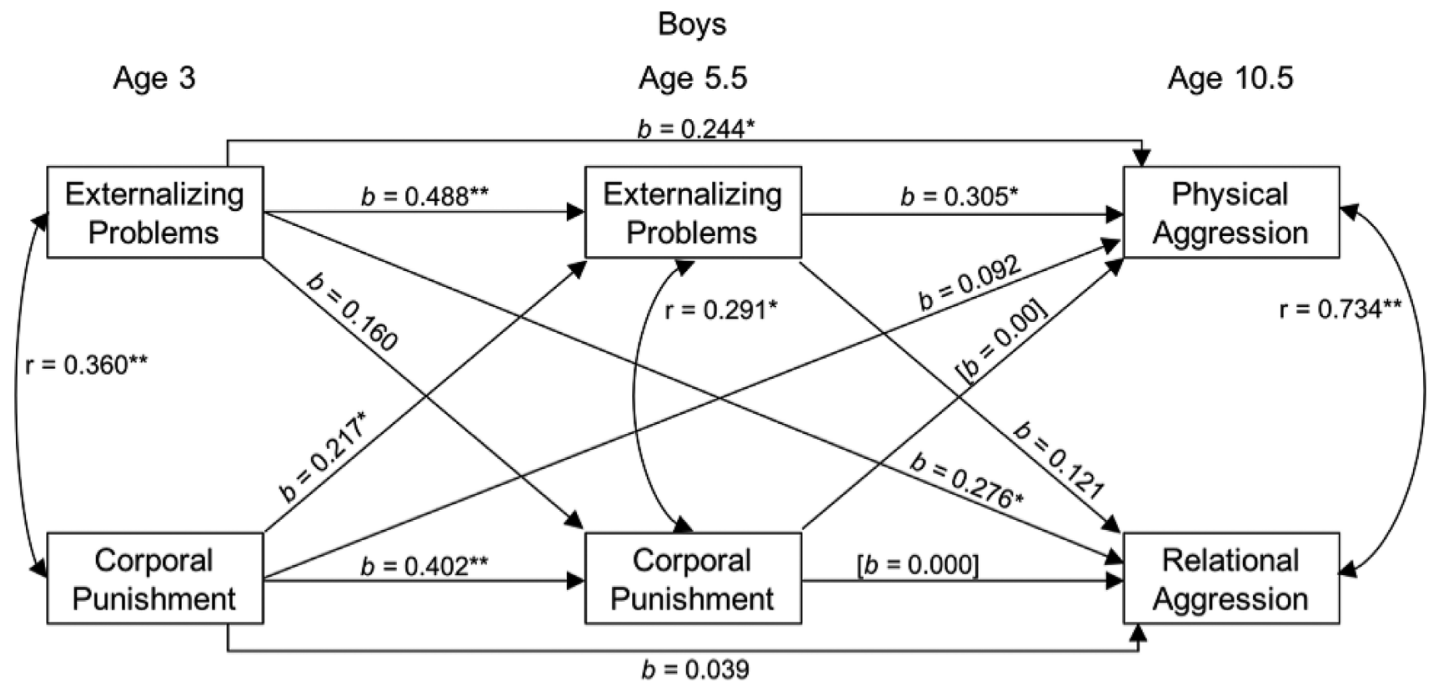

FIGURE 2 Cross-lagged panel analysis of T1 and T2 externalizing problems and corporal punishment predicting T3 physical and relational aggression among boys. Shown are standardized regression coefficients $(b)$ and correlations ( $r$ ) for path models predicting adolescent (T3) physical and relational peer aggression from early childhood (T1 and T2) externalizing problems and corporal punishment. The [bracketed] pathways between T2 harsh discipline and T3 outcomes was fixed at zero as they were found to be n.s. Coefficients signified with an asterisk are significant. ${ }^{*} p<.05,{ }^{* *} p<.01$ 
Girls

Age 3

Age 5.5

Age 10.5

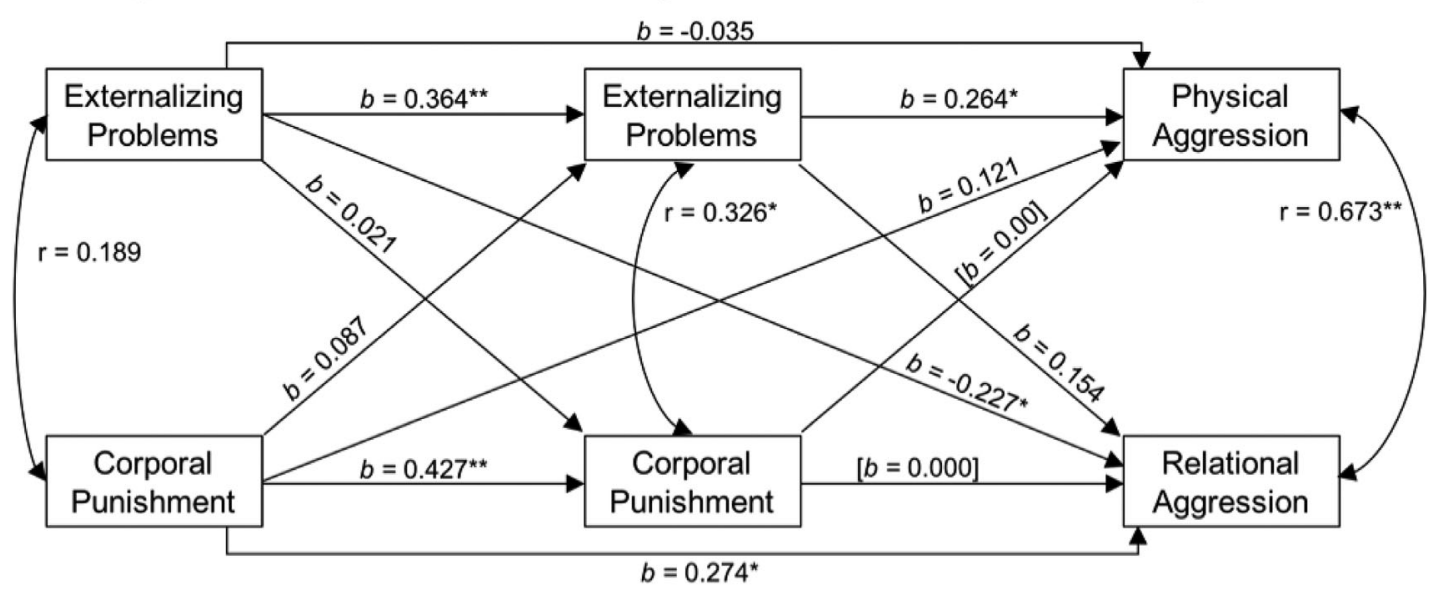

FIGURE 3 Cross-lagged panel analysis of T1 and T2 externalizing problems and corporal punishment predicting T3 physical and relational aggression among girls. Shown are standardized regression coefficients $(b)$ and correlations $(r)$ for path models predicting adolescent (T3) physical and relational peer aggression from early childhood (T1 and T2) externalizing problems and corporal punishment. The [bracketed] pathways between T2 harsh discipline and T3 outcomes was fixed at zero as they were found to be n.s. Coefficients signified with an asterisk are significant. ${ }^{*} p<.05,{ }^{* *} p<.01$

\section{8 | DISCUSSION}

Our main goal was to test a longitudinal model linking early corporal punishment and early externalizing problems to physical and relational peer aggression in preadolescence, and to examine how these pathways differed by child sex. Using both boys and girls from the sample, we found three developmental pathways to specific forms of peer aggression in preadolescence: (i) direct associations between stable childhood externalizing problems and later physical aggression; (ii) a direct pathway from early corporal punishment to preadolescent relational and physical peer aggression; and (iii) an indirect pathway from early corporal punishment to later physical aggression via continuing externalizing problems in middle childhood. Further analyses revealed that the strength, nature, and direction of these associations differed for boys and girls. Early externalizing problems predicted later physical aggression for both boys and girls, but the association was more robust for boys, whereas early corporal punishment predicted preadolescent relational aggression only for girls. Strikingly, we found that the direction of associations between preschool externalizing problems and preadolescent relational aggression differed by sex, such that high preschool externalizing problems predicted higher levels of relational aggression for boys but lower levels of relational aggression for girls. These findings significantly build on, and in some ways challenge, literature on the development of peer aggression.

Our findings advance knowledge of peer aggression by explicating distinct pathways to physical versus relational peer aggression that potentially result from specific early childhood risk factors and developmental timing. We found that not only did elevated levels of externalizing problems in the early school-age years (T2) predict later physical aggression, but that stability of externalizing problems (from T1 to T2) did as well. Our findings augment previous work by showing that preschoolers with high levels of externalizing problems who continue to struggle with aggressive impulses following the transition to school are at an elevated risk for establishing conflicted and coercive relationships with peers in preadolescence (Hughes et al., 2000; Keown \& Woodward, 2006; Olson et al., 2011), specifically via the use of physical peer aggression. Our findings also complement previous findings that children who show persistent externalizing problems across development are at an increased risk for diverse adjustment problems (Barker et al., 2008; Lansford et al., 2010; Moffitt, 2003; Moffitt \& Caspi, 2001).

The present findings refine our understanding of associations between early corporal punishment and the development of physical versus relational peer aggression. First, corporal punishment during the early preschool period was indirectly related to preadolescent physical aggression through increased externalizing problems. Corporal punishment provides parents with a power-assertive means of eliciting immediate compliance and allows them to demonstrate their physical dominance over children. Moreover, high levels of physical discipline are often accompanied by a parent's negative emotions such as anger, hostility, and frustration (Critchley \& Sanson, 2006). Receiving corporal punishment during preschool, a time when children are rapidly developing, may disrupt a child's ability to learn emotion regulation and conflict resolution skills. Thus, corporal punishment may not only model inappropriate externalizing behavior (such as screaming and hitting) but also disrupt a child's ability to develop appropriate conflict management skills, placing them at risk for the development of persistent externalizing problems.

Additionally, to the best of our knowledge, our study is the first to show that corporal punishment in preschool directly predicts both preadolescent relational and physical peer aggression regardless of child sex. By considering both boys and girls, as well as multiple time points, we showed that corporal punishment in preschool is associated 
with children's later peer adjustment by increasing their risk for both physical and relational peer aggression. The fact that corporal punishment predicts peer aggression is not surprising given that parental physical discipline models both relational and physical dominance vis-a-vis their children (Choe et al., 2013). What is more striking is that receiving corporal punishment in preschool, not the early school-age years, predicts children's interactions with peers into the preadolescent years. This finding suggests that the preschool years may represent a sensitive period in which exposure to corporal punishment sets the stage for later peer aggression well into preadolescence. Taken together, our findings suggest that parental behavior in early childhood may be a stronger predictor of both forms of peer aggression in preadolescence, compared to a child characteristic, externalizing behavior. This was demonstrated by our findings of a direct pathway from preschool corporal punishment to both forms of later peer aggression, and of an indirect pathway from corporal punishment to physical aggression via child externalizing problems.

In terms of sex differences, we found that pathways to physical and relational peer aggression differed for boys and girls. For boys, preschool externalizing problems drove the link to later physical and relational peer aggression, which is consistent with prior research (Gazelle \& Ladd, 2003; Schwartz, 2000). For girls, corporal punishment positively predicted relational peer aggression. These findings are consistent with prior studies showing that boys and girls respond to harsh parental discipline differently (Gershoff, 2002; Patterson et al., 1992). Our study takes this further by showing that corporal punishment in preschool may have a lasting impact by predicting later relational aggression for girls.

A striking and unexpected finding was that preschool externalizing behavior negatively predicted later relational aggression in girls, but positively predicted relational aggression for boys. This finding may highlight the potentially different set of skills and behavior that underlie relational aggression in boys and girls as well as how gender socialization and group dynamics influence the type of peer aggression used. Relational peer aggression in girls may require greater social comportment, social cognition, and behavioral self-regulation that would not be observed among physical peer aggressors (Andreou, 2006; Kaukiainen et al., 1999; Vaillancourt et al., 2003). This may be because girls are taught from an early age the importance of using language and expressing their feelings in order to form intimate relationships. It is possible that girls who display high levels of early externalizing behavior do not develop the strong social skills, networks, and relationships that may be implicated in later relational peer aggression and therefore girls who lack these skills are more likely to use physical rather than relational peer aggression. The opposite may be true of boys. According to our data, boys who show early externalizing problems display both physical and relational peer aggression in the pre-adolescent years. This may be because boys are taught from an early age that they can utilize physical and instrumental means, such as power and physical dominance, to get what they want. These forms of behavior are not at odds with what is seen in children with externalizing problems (e.g., aggression, impulsivity). The differences seen between gender socialization for boys and girls as well as the dynamics of the female and male peer group, may explain why boys who display early externalizing problems use both physical and relational peer aggression later in life whereas girls who show early externalizing behavior are less likely to use relational peer aggression.

Taken together, our findings suggest that parental behavior uniquely contributes to the development of relational peer aggression among girls, whereas early onset externalizing problems appear central to the development of both forms of peer aggression among boys. Our findings have important clinical implications. To date, parent management training (PMT; Kazdin, 1997) and parent-child interaction therapy (PCIT; Eyberg, Boggs, \& Algina, 1995) are the most widely used evidence-based treatments for early disruptive behavior in both girls and boys. Theorists who espouse these interventions view child behavior and parenting practices as highly intertwined and thus target both child externalizing behavior and maladaptive parenting techniques such as harsh parental discipline (Patterson, 1982; Patterson et al., 1992). Considering our child sex specific findings, the success of these treatments for both boys and girls may be due to different factors. Our findings present another compelling case for early intervention, and that changes in parent management skills may affect child adjustment outcomes through different mechanisms in girls and boys.

\section{1 | Strengths and limitations}

Noteworthy strengths of our study included prospective longitudinal assessments of children's peer aggression across an important developmental transition; assessments of early developmental risk that spanned multiple constructs and informants; assessment of both physical and relational peer aggression; the participation of relatively equal numbers of boys and girls; and consideration of interrelations between intrachild and parenting risk factors. We also highlight features of this study that may limit the generalizability of our findings. Children in the study were drawn from a community sample of mostly European American, two-parent, middle-class families, and thus findings may not generalize to children growing up in different family settings.

Our study was a secondary analysis of an established data set which constrained some measurement considerations. When the study began the Child Behavior Checklist (CBCL) 1.5-5 years (Achenbach \& Rescorla, 2001) had not been created and therefore the CBCL/2-3 (Achenbach, 1992), which has good psychometric characteristics, was utilized. In addition, we decided the best way to assess both physical and relational peer aggression using available measures was to use the Dodge Inventory of Peer Relations scale to measure physical peer aggression and a subset of the Crick's Children's Social Behavior Scale to measure relational aggression. We acknowledge that by choosing these measures we relied on teacher reports of both physical and relational peer aggression which may be a limitation because teachers may not be fully aware of all forms of peer aggression, especially relationally aggressive strategies. Additionally, our measure of corporal punishment did not include damaging emotional behavior such as screaming, yelling, and/or derogating the child. Given the unique findings of our study, as a field we should 
begin to focus on the full spectrum of harsh parental disciplinary behavior that may be related to adverse child outcomes.

We also acknowledge that relational and physical peer aggression are moderately correlated (Crick et al., 1997; Crick et al., 2006). Nonetheless, we treated them as discrete outcomes because early childhood precursors of later relational aggression have been less frequently studied than those leading to physical forms of peer aggression. Finally, because our study aim was to look preschool and school-age predictors of later peer aggression rather than stability of peer aggression overtime we did not control for previous peer aggression. In fact, we removed aggression items from the $\mathrm{CBCL}$ to demonstrate that our study was showing that externalizing behavior, not early aggression, predicted later peer aggression.

\section{9 | CONCLUSION}

The present study was, to our knowledge, the first to assess the interplay of externalizing behavior and corporal punishment as developmental pathways to elevated levels of children's physical versus relational peer aggression in preadolescence. These findings advance our understanding of peer aggression by explicating distinct pathways to physical versus relational forms of peer aggression that reflect specific early childhood risk factors and developmental timing. We found that stability of externalizing behavior across early development predicted later physical peer aggression and that there were direct pathways from corporal punishment in the early preschool years to children's later relational and physical peer aggression. Furthermore, parental behavior and child characteristics in the early preschool period played unique roles in the development of preadolescent peer aggression for boys and girls. Thus, our data highlight the need for parental and child level interventions that begin in early childhood.

\section{ORCID}

Courtney A. Zulauf iD http://orcid.org/0000-0001-7236-4987

\section{REFERENCES}

Achenbach, T. M. (1991). Manual for the child behavior checklist/4-18 and 1991 profiles. Burlington, VT: University of Vermont Department of Psychiatry. Social Development from Infancy to Adolescence.

Achenbach, T. M. (1992). Manual for the child behavior checklist/2-3 and 1992 profile: Profile for boys and girls. Auswertungsbögen: Department of Psychiatry, University of Vermont.

Achenbach, T. M., \& Rescorla, L. A. (2001). Manual for the ASEBA school-age forms and profiles: An integrated system of multi-informant assessment. Burlington, VT: Research Center for Children, Youth, and Families.

Andreou, E. (2006). Social preference, perceived popularity and social intelligence relations to overt and relational aggression. School Psychology International, 27, 339-351.

Archer, J., \& Coyne, S. M. (2005). An integrated review of indirect, relational, and social aggression. Personality and Social Psychology Review, 9, 212-230. https://doi.org/10.1207/s15327957pspr0903

Barker, E. D., Boivin, M., Brendgen, M., Fontaine, N., Arseneault, L., Vitaro, F., ... Tremblay, R. E. (2008). Predictive validity and early predictors of peer-victimization trajectories in preschool. Archives of General Psychiatry, 65, 1185-1192. https://doi.org/10.1001/archpsyc. 65.10 .1185

Bjorklund, D. F., \& Pellegrini, A. D. (2000). Child development and evolutionary psychology. Child Development, 71, 1687-1708. https:// doi.org/10.1111/1467-8624.00258

Björkqvist, K., Österman, K., Lagerspetz, K. M., Landau, S. F., Caprara, G. V., \& Fraczek, A. (2001). Aggression, victimization and sociometric status: Findings from Finland, Israel, Italy and Poland. In J. M. Rameriez \& D. S. Richardson (Eds.), Crosscultural approaches to aggression and reconciliation (pp. 111-119). Huntington, NY: Nova Science.

Boivin, M., Petitclerc, A., Feng, B., \& Barker, E. D. (2010). The developmental trajectories of peer victimization in middle to late childhood and the changing nature of their behavioral correlates. Merrill-Palmer Quarterly, 56, 231-260. https://doi.org/10.1353/mpq.0.0050

Campbell, S. B., Shaw, D. S., \& Gilliom, M. (2000). Early externalizing behavior problems: Toddlers and preschoolers at risk for later maladjustment. Development and Psychopathology, 12, 467-488. https://doi.org/10.1017/s0954579400003114

Campbell, S. B., Spieker, S., Vandergrift, N., Belsky, J., \& Burchinal, M. (2010). Predictors and sequelae of trajectories of physical aggression in school-age boys and girls. Development and Psychopathology, 22, 133-150. https://doi.org/10.1017/s0954579409990319

Choe, D. E., Olson, S. L., \& Sameroff, A. J. (2013). The interplay of externalizing problems and physical and inductive discipline during childhood. Developmental Psychology, 49, 2029-2039. https://doi.org/ 10.1037/a0032054

Crick, N. R. (1996). The role of overt aggression, relational aggression, and prosocial behavior in the prediction of children's future social adjustment. Child Development, 67, 2317-2327. https://doi.org/ 10.2307/1131625

Crick, N., Ostrov, J., \& Kawabata, Y. (2007). Gender differences in aggression and violence. In I. Waldman, D. J. Flannery, and A. T. Vazsonyi (Eds.), The Cambridge handbook of violent behavior. Cambridge University Press.

Crick, N. R., Casas, J. F., \& Ku, H. (1999). Physical and relational peer victimization in preschool. Developmental Psychology, 35, 376-385.

Crick, N. R., Casas, J. F., \& Mosher, M. (1997). Relational and overt aggression in preschool. Developmental Psychology, 33, 579-588. https://doi.org/10.1037/0012-1649.35.2.376

Crick, N. R., \& Grotpeter, J. K. (1995). Relational aggression, gender, and social-psychological adjustment. Child Development, 66, 710-722. https://doi.org/10.2307/1131945

Crick, N. R., Ostrov, J. M., \& Werner, N. E. (2006). A longitudinal study of relational aggression, physical aggression, and children's social-psychological adjustment. Journal of Abnormal Child Psychology, 34, 127-138. https://doi.org/10.1007/s10802-005-9009-4

Critchley, C. R., \& Sanson, A. V. (2006). Is parent disciplinary behavior enduring or situational? A multilevel modeling investigation of individual and contextual influences on power assertive and inductive reasoning behaviors. Journal of Applied Developmental Psychology, 27, 370-388. https://doi.org/10.1016/j.appdev.2006.04.006

Deater-Deckard, K., \& Dodge, K. A. (1997). Externalizing behavior problems and discipline revisited: Nonlinear effects and variation by culture, context, and gender. Psychological Inquiry, 8, 161-175. https://doi.org/ 10.1207/s15327965pli0803_1

Dodge, K. A., \& Coie, J. D. (1987). Social-information-processing factors in reactive and proactive aggression in children's peer groups. Journal of Personality and Social Psychology, 53, 1146-1158. https://doi.org/ 10.1037/0022-3514.53.6.1146

Dodge, K. A., Pettit, G. S., \& Bates, J. E. (1994). Socialization mediators of the relation between socioeconomic status and child conduct problems. Child Development, 65, 649-665. https://doi.org/10.2307/1131407

Eyberg, S. M., Boggs, S. R., \& Algina, J. (1995). Parent-child interaction therapy: A psychosocial model for the treatment of young children with 
conduct problem behavior and their families. Psychopharmacology Bulletin, 31, 83-91.

Gazelle, H., \& Ladd, G. W. (2003). Anxious solitude and peer exclusion: A diathesis-stress model of internalizing trajectories in childhood. Child Development, 74, 257-278. https://doi.org/10.1111/1467-8624. 00534

Gershoff, E. T. (2002). Corporal punishment by parents and associated child behaviors and experiences: A meta-analytic and theoretical review. Psychological Bulletin, 128, 539-579. https://doi.org/10.1037/00332909.128.4.539

Hanish, L. D., \& Guerra, N. G. (2002). A longitudinal analysis of patterns of adjustment following peer victimization. Development and Psychopathology, 14, 69-89. https://doi.org/10.1017/s0954579402001049

Hollingshead, W. (1979). The Hollingshead four-factor index of socioeconomic status. New Haven, CT: Unpublished manuscript, Yale University.

Hughes, C., White, A., Sharpen, J., \& Dunn, J. (2000). Antisocial, angry, and unsympathetic: "Hard-to-manage" preschoolers' peer problems and possible cognitive influences. Journal of Child Psychology and Psychiatry, 41, 169-179. https://doi.org/10.1017/s0021963099005193

Kaukiainen, A., Björkqvist, K., Lagerspetz, K., Österman, K., Salmivalli, C., Rothberg, S., \& Ahlbom, A. (1999). The relationships between social intelligence, empathy, and three types of aggression. Aggressive Behavior, 25, 81-89. https://doi.org/10.1002/(SICI)1098-2337(1999)25:2

Kazdin, A. E. (1997). Parent management training: Evidence, outcomes, and issues. Journal of the American Academy of Child \& Adolescent Psychiatry, 36, 1349-1356. https://doi.org/10.1097/00004583-19971000000016

Keane, S. P., \& Calkins, S. D. (2004). Predicting kindergarten peer social status from toddler and preschool problem behavior. Journal of Abnormal Child Psychology, 32, 409-423. https://doi.org/10.1023/B: JACP.0000030294.11443.41

Kenny, D. A., Kaniskan, B., \& McCoach, D. B. (2015). The performance of RMSEA in models with small degrees of freedom. Sociological Methods \& Research, 44, 486-507. https://doi.org/10.1177/0049124114543236

Keown, L. J., \& Woodward, L. J. (2006). Preschool boys with pervasive hyperactivity: Early peer functioning and mother-child relationship influences. Social Development, 15, 23-45. https://doi.org/10.1111/ j.1467-9507.2006.00328.x

Kline, T. J. (2005). Psychological testing: A practical approach to design and evaluation. Thousand Oaks, CA: Sage Publications.

Kochenderfer-Ladd, B., \& Skinner, K. (2002). Children's coping strategies: Moderators of the effects of peer victimization? Developmental Psychology, 38, 267-278. https://doi.org/0.1037/0012-1649.38.2.267

Lansford, J. E., Malone, P. S., Dodge, K. A., Pettit, G. S., \& Bates, J. E. (2010). Developmental cascades of peer rejection, social information processing biases, and aggression during middle childhood. Development and Psychopathology, 22, 593-602. https://doi.org/10.1017/s09545 79410000301

Leadbeater, B. J., \& Hoglund, W. L. (2009). The effects of peer victimization and physical aggression on changes in internalizing from first to third grade. Child Development, 80, 843-859. https://doi.org/10.1111/ j.1467-8624.2009.01301.x

Little, R. J. (1988). A test of missing completely at random for multivariate data with missing values. Journal of the American Statistical Association, 83, 1198-1202. https://doi.org/10.1080/01621459.1988. 10478722

McQuade, J. D., Breaux, R. P., Miller, R., \& Mathias, L. (2017). Executive functioning and engagement in physical and relational aggression among children with ADHD. Journal of Abnormal Child Psychology, 45, 899-910. https://doi.org/10.1007/s10802-016-0207-z

Merrell, K. W., Buchanan, R., \& Tran, O. K. (2006). Relational aggression in children and adolescents: A review with implications for school settings. Psychology in the Schools, 43, 345-360. https://doi.org/10.1002/ pits. 20145
Moffitt, T. E. (1993). Adolescence-limited and life-course-persistent antisocial behavior: A developmental taxonomy. Psychological Review, 100, 674. https://doi.org/10.1037/0033-295X.100.4.674

Moffitt, T. E. (2003). Life-course-persistent and adolescence-limited antisocial behavior: A 10-year research review and a research agenda. In B. B. Lahey, T. E. Moffitt, \& A. Caspi (Eds.), Causes of conduct disorder and juvenile delinquency (pp. 49-75). New York: Guilford Press.

Moffitt, T. E., \& Caspi, A. (2001). Childhood predictors differentiate lifecourse persistent and adolescence-limited antisocial pathways among males and females. Development and Psychopathology, 13, 355-375. https://doi.org/10.1017/s0954579401002097

Olson, S. L., Lopez-Duran, N., Lunkenheimer, E. S., Chang, H., \& Sameroff, A. J. (2011). Individual differences in the development of early peer aggression: Integrating contributions of self-regulation, theory of mind, and parenting. Development and Psychopathology, 23, 253-266. https:// doi.org/10.1017/s0954579410000775

Olson, S. L., Sameroff, A. J., Kerr, D. C., Lopez, N. L., \& Wellman, H. M. (2005). Developmental foundations of externalizing problems in young children: The role of effortful control. Development and Psychopathology, 17, 25-45. https://doi.org/10.1017/s0954579405050029

Ostrov, J. M., \& Godleski, S. A. (2010). Toward an integrated gender-linked model of aggression subtypes in early and middle childhood. Psychological Review, 117, 233-242. https://doi.org/10.1037/a0018070

Park, J. H., Essex, M. J., Zahn-Waxler, C., Armstrong, J. M., Klein, M. H., \& Goldsmith, H. H. (2005). Relational and overt aggression in middle childhood: Early child and family risk factors. Early Education and Development, 16, 233-258. https://doi.org/10.1080/10409289. 2005.10472869

Patterson, G. (1982). Coercive family process. Eugene, OR: Castalia.

Patterson, G. R., Reid, J. B., \& Dishion, T. J. (1992). Antisocial boys: A social interactional approach (Vol. 4). Eugene, OR: Castalia.

Pellegrini, A. D., \& Bartini, M. (2001). Dominance in early adolescent boys: Affiliative and aggressive dimensions and possible functions. MerrillPalmer Quarterly, 47, 142-163. https://doi.org/10.1353/mpq.2001 .0004

Renouf, A., Brendgen, M., Parent, S., Vitaro, F., David Zelazo, P., Boivin, M., ... Séguin, J. R. (2010). Relations between theory of mind and indirect and physical aggression in kindergarten: Evidence of the moderating role of prosocial behaviors. Social Development, 19, 535-555. https:// doi.org/10.1111/j.1467-9507.2009.00552.x

Rosseel, Y. (2012). Lavaan: An $\{R\}$ package for structural equation modeling. Journal of Statistical Software, 48, 1-36.

Salmivalli, C., \& Kaukiainen, A. (2004). "Female aggression" revisited: Variable-and person-centered approaches to studying gender differences in different types of aggression. Aggressive Behavior, 30, 158-163. https://doi.org/10.1002/ab.20012

Schwartz, D. (2000). Subtypes of victims and aggressors in children's peer groups. Journal of Abnormal Child Psychology, 28, 181-192. https://doi. org/10.1023/A:1005174831561

Schwartz, D., Dodge, K. A., Pettit, G. S., \& Bates, J. E. (2000). Friendship as a moderating factor in the pathway between early harsh home environment and later victimization in the peer group. Developmental Psychology, 36, 646-662. https://doi.org/10.1037/0012-1649.36.5.646

Shields, A., Ryan, R. M., \& Cicchetti, D. (2001). Narrative representations of caregivers and emotion dysregulation as predictors of maltreated children's rejection by peers. Developmental Psychology, 37, 321-337. https://doi.org/10.1037/0012-1649.37.3.321

Snyder, J., Cramer, A., Afrank, J., \& Patterson, G. R. (2005). The contributions of ineffective discipline and parental hostile attributions of child misbehavior to the development of conduct problems at home and school. Developmental Psychology, 41, 30. https://doi.org/10.1037/ 0012-1649.41.1.30

Spieker, S. J., Campbell, S. B., Vandergrift, N., Pierce, K. M., Cauffman, E., Susman, E. J., \& Roisman, G. I. (2012). Relational aggression in middle 
childhood: Predictors and adolescent outcomes. Social Development, 21 354-375. https://doi.org/10.1111/j.1467-9507.2011.00631.x

Underwood, M. K., Galenand, B. R., \& Paquette, J. A. (2001). Top ten challenges for understanding gender and aggression in children: Why can't we all just get along? Social Development, 10, 248-266. https:// doi.org/10.1111/1467-9507.00162

Vaillancourt, T., Brendgen, M., Boivin, M., \& Tremblay, R. E. (2003). A longitudinal confirmatory factor analysis of indirect and physical aggression: Evidence of two factors over time? Child Development, 74, 1628-1638. https://doi.org/10.1046/j.1467-8624.2003. 00628.x
How to cite this article: Zulauf CA, Sokolovsky AW, Grabell AS, Olson SL. Early risk pathways to physical versus relational peer aggression: The interplay of externalizing behavior and corporal punishment varies by child sex.

Aggressive Behavior. 2018;44:209-220.

https://doi.org/10.1002/ab.21744 